\section{Do district health systems perform differently because of their managers? Preliminary insights from Indonesia}

\author{
Augustine Asante, ${ }^{1}$ Sandi Iljanto, ${ }^{2}$ \\ John Rule, ${ }^{1}$ Jennifer Doyle ${ }^{1}$ \\ 'School of Public Health and Community \\ Medicine, UNSW Australia, Sydney, \\ Australia \\ ${ }^{2}$ Faculty of Public Health, Centre for \\ Health Administration, Management and \\ Policy, University of Indonesia, Jakarta, \\ Indonesia
}

\begin{abstract}
District health systems (DHS) are central to the global efforts to improve health outcomes but many remain ineffective. In many lowresource settings, despite the generally weak DHS there is evidence that some districts consistently perform well against the odds, and this is often attributed to the calibre of managers leading such districts and their management and leadership (M\&L) skills. This paper examines the M\&L practices of district health managers in high and low performing districts in Indonesia in an attempt to understand whether the differences in the performance of DHS can be explained, at least in part, by the differences in the performance of their health managers. We employed a mixed methods case study design focusing on two purposefully selected districts. Data were collected in 2011 using questionnaires and in-depth interviews. The preliminary results suggest that M\&L practices of managers in the high and low performing districts are similar and provide little explanation for the differences in the performance of the two DHS. Contextual and health system factors offered a much better explanation for the variations in DHS performance.
\end{abstract}

\section{Introduction}

District health systems (DHS) are pivotal to the delivery of basic health services and achievement of the health millennium development goals (MDGs). In low- and middleincome countries (LMICs) DHS are usually comprised of community health centres, networks of local facilities delivering primary health care (PHC) and outreach services, and district hospitals that receive referrals from health centres. ${ }^{1}$

Efforts to strengthen DHS globally date back many years and have had varying degrees of success. In countries such as Thailand, the local health system functions relatively well through an established system of financing and network of providers. ${ }^{2}$ In other Southeast Asian countries including the Philippines and Indonesia, efforts to strengthen DHS are linked to a radical policy of decentralization of healthcare systems with the devolution of health services to local governments. ${ }^{3}$ Such restructuring may affect the performance and equity of health systems. ${ }^{4}$ Within countries there may be variations in the performance of DHS. In South Africa the District Health Barometer 2010/11 shows significant differences in the performance of DHS across a wide range of health indicators. ${ }^{5}$ It is widely believed that the calibre of health managers who lead the DHS, particularly their management and leadership skills, has much to do with the differences in the performance of DHS. ${ }^{6,7}$

In 2007, the World Health Organization (WHO) sponsored international consultations on management and leadership (M\&L) in lowincome countries concluded that weak M\&L capacity is a barrier to effective health systems including DHS. ${ }^{7}$ Strengthening M\&L capacity has been an integral part of the global efforts to improve the effectiveness of health systems including the DHS. Despite this, M\&L capacity is generally weak in many low-resource settings and the need to identify effective interventions for improving the capacity and performance remains urgent. ${ }^{6,7}$

Indonesia is a middle-income country and the largest economy in Southeast Asia. The Government of Indonesia has prioritised PHC, committed to implementing universal health coverage, and to reducing maternal mortality. ${ }^{8}$ The effectiveness of the DHS and the performance of its managers are crucial to achieving these goals. As part of the efforts to strengthen DHS, the Indonesian Ministry of Health $(\mathrm{MoH})$ assesses and ranks districts by performance using a health development index created by its National Institute of Health Research and Development (NIHRD) and some districts perform relatively better than others. ${ }^{9}$

In this study, two groups of health service managers selected from a high and a low performing district were examined in an attempt to understand why some DHS perform relatively better than others and the role M\&L practices play in improving DHS performance. As an exploratory study, the objective was not to attribute effective M\&L practices to improved DHS performance at this stage but to use the findings as a basis for a follow up study that will assess more comprehensively the link between M\&L practices and DHS performance. The study was part of a broader collaborative project between the University of New South Wales (Human Resources for Health Knowledge Hub), the Centre for Health Service
Correspondence: Augustine Asante, School of Public Health and Community Medicine, Faculty of Medicine, UNSW Australia, Sydney NSW 2052, Australia.

Tel: +61.2.93858683 - Fax: +61.2.93136185.

E-mail: a.asante@unsw.edu.au

Acknowledgements: we acknowledge the input of Dr. Graham Roberts and other staff of the Human Resources for Health Knowledge Hub, UNSW Australia.

Contributions: AA conceived and designed the study; he oversaw the data analysis and drafting of the manuscript. SI oversaw the data collection and contributed to the data analysis and drafting of the manuscript. JR and JD contributed to data analysis and drafting of the manuscript. All authors reviewed the final draft of the manuscript.

Conflict of interest: the authors declare no potential conflict interest.

Funding: this study was carried out as part of the activities of the Human Resources for Health Knowledge Hub which was funded by the Australian Aid. The views and opinions expressed therein are those of the authors and do not necessarily reflect those of the Australian Aid.

Key words: District health systems; Health managers; Indonesia; Management and leadership; Performance.

Received for publication: 28 June 2014.

Revision received: 28 August 2014.

Accepted for publication: 26 September 2014

This work is licensed under a Creative Commons Attribution 3.0 License (by-nc 3.0).

(C) Copyright A. Asante et al., 2015

Licensee PAGEPress, Italy

Healthcare in Low-resource Settings 2015; 3:4471 doi:10.4081/hls.2015.4471

Management, Universitas Gadjah Mada (UGM) and researchers from University of Indonesia. Ethics approval was obtained from the UGM Ethics Committee with permission from Provincial Health Authorities.

\section{Materials and Methods}

\section{Design}

This investigation employs a mixed methods case study design focusing on two purposefully selected districts in the West Java province - one relatively high performing (District A) and one low performing (District B). The definition of high and low performing districts was based on the 2008 NIHRD ranking of health districts. ${ }^{9}$ Two sets of indicators comprising 10 generic measures in each set 
were used to assess the M\&L practices of health managers in the two districts (Table 1).

The indicators covered some of the basic $\mathrm{MoH}$ functions of district health managers and were put together in consultation with the provincial health authority and after reviewing the published and grey international and local literature. The leadership indicators were used to assess the leadership practices of the head of the DHO as the designated manager.

\section{Data collection}

Data were collected in 2011 from three levels of the health system - provincial, DHO and facility. At the provincial level two in-depth interviews were conducted with senior officials of the provincial health office (PHO) exploring issues around i) M\&L practices of the DHO managers and ii) the differences in performance of the various DHS in the province. This information was used to triangulate data obtained from district managers. At the DHO level we used researcher-administered questionnaires and in-depth interviews to gather data on a range of issues including supervision, performance evaluation and personnel administration from five officials with managerial responsibilities including the head of the $\mathrm{DHO}$. Finally, at the facility level we used semi-structured interviews to elicit views on M\&L practices of the DHO manager and general information about health delivery in the district.

We used snowball sampling approach to recruit participants. Verbal permission was obtained from heads of various levels who recommended other managers whom we could approach and invite to take part in the study. Consent was obtained from each participant. In total, we conducted 20 interviews in the two districts: ten at the DHO level (five in each district), eight at the health centre level (four in each district) and two at the provincial level (Figure 1).

\section{Data analysis}

We developed a simple scoring system to analyze the data. For the quantitative questions that explored whether a management activity (denoted by an indicator) was carried out by the district team, we assigned a score of 0 to a negative (no) response and 1 to a positive (yes) response. A further score of $0,0.5$, or 1 was assigned if the qualitative account of the respondent suggested that the activity was rarely, partially or routinely carried out. Where possible, we triangulated the information obtained at the DHO level with data from the provincial and health centre levels to ensure reliability. The total score of each of the 10 indicators were aggregated to get the final district score. For the leadership indicators the questions were on a Likert scale and were scored from 0 (strongly disagree) to 4 (strongly agree). A maximum score of 16 per indicator was derived from the four respondents in each district. This was scaled down to 10 to give a total score of 100 for all the ten indicators.

\section{Results}

\section{Characteristics of managers}

All 10 respondents from the two DHOs were aged between 47 and 54 years and seven were female. Eight of the 10 were eligible to retire within the next five years in compliance with the official Indonesian civil service retirement age of 55 years for staff in structural (managerial) positions. The primary professional qualifications were predominantly medicine and dentistry (two GPs and two dentists from each district). All respondents had worked in the health service for over 15 years with most of them working their way up from the sub-district level. Nearly all reported spending $100 \%$ of their time on management issues, contradicting the general assumption that health managers often perform dual roles as managers and clinicians. The majority of respondents indicated, however, that they practice privately as clinicians or dentists after office hours.

Formal training in management was limited; six of the 10 respondents had no management qualification. However, all 10 had attended a short training program in leadership and health administration conducted for structural staff in the public sector by the regional civil service agency (Badan Ketenagaan Daerah - BKD).

\section{Management and leadership practices}

\section{Knowledge of responsibilities and use of manuals}

Management roles and functions were performed to a similar degree in the two districts. All respondents indicated that they were fully aware of their management responsibilities and that detailed written job descriptions including responsibilities and authority had been provided with their appointment letters. They also confirmed that there were standard operating manuals and guidelines for all pro-

Table 1. Indicators for assessing management and leadership practices of managers.

\begin{tabular}{ll} 
Management indicators & Leadership indicators \\
Know responsibilities as manager & Listen to staff \\
Have and use procedural manuals & Understand the needs of staff \\
\hline Undertake routine staff assessment & Treat staff as individuals \\
Provide timely feedback on staff assessment & Set good work examples worth emulating \\
\hline Handle staff disciplinary matters effectively & Motivate and encourages staff \\
Request drugs and supplies on time & Handle staff matters fairly and consistently \\
\hline Undertake regular staff supervisory visits & Acknowledge jobs well done \\
Have regular technical meetings & Handle disciplinary matters without any bias \\
\hline Use health data for decision making & Show concern for staff career advancement \\
Collaborate with the non-government sectors & Generally enjoy the respect of staff \\
\hline
\end{tabular}

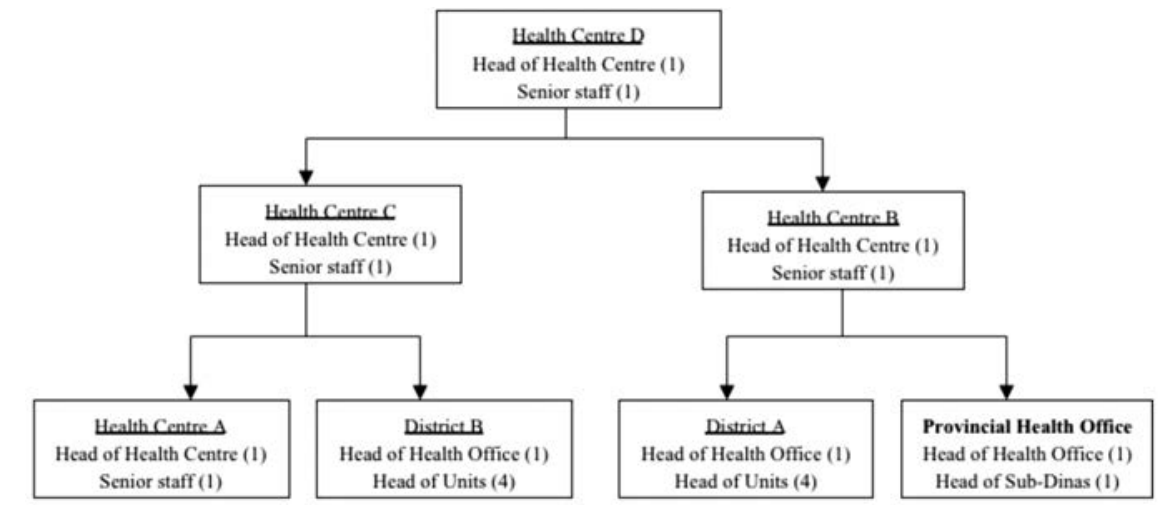

Figure 1. Number and location of interviews. 
grams, which were adjusted as required for local conditions. However, it should be noted that interview data from both districts suggest that the manuals were mainly technical manuals guiding program implementation and not for personal administration purposes (Table 2).

Overall, there appeared to be a strong culture of referring to formal, written guidelines with the majority of respondents stating that they must always adhere to the rules and regulations or steps that are described in the technical guidelines. The use of manuals appeared more strongly observed in District A than B (Table 2).

\section{Performance assessment and feedback}

The data from the DHO level indicate that some form of staff performance assessment was carried out although there was no consensus on the frequency of such assessment; reported frequency ranged from once every three months to once a year. Respondents explained that the performance assessment process was hierarchically arranged with the DHO head being evaluated by the head of the district (bupati), then he/she evaluates the other managers (unit heads) at the DHO who in turn evaluate their subordinates in the subdistricts. They further explained that a standard civil servant performance evaluation form known as Assessment of Working Performance (Daftar Penilaian Pelaksanaan Pekerjaan or DP3) was used for assessment with the results used mainly for staff promotion purposes. Some respondents expressed dissatisfaction with the DP3-based assessment, indicating it does not assist them to improve upon their performance: It (DP3-based assessment) is not helpful because it is just normative; sometimes I don't understand how... It should be filled out differently for each person, right? But it is not... To me, it is better not to use the DP3. I mean if we are assessing performance, it must be different between staff; some are diligent; some are not but still good in other areas. For example, I often perform tasks that are not listed in my Tupoksi (job description) but are very important, DP3 won't consider that (District A DHO level respondent).

There was no agreement among the respondents at the DHO level as to whether written feedback on performance (other than the duplicate copy of the completed DP3) was given to staff. However, data from the health centre level in both districts clearly suggest that no written feedback on performance (aside the DP3 duplicate copy) was given.

\section{Staff supervision and disciplinary matters}

Supervision of health centres was regarded by respondents in both $\mathrm{DHOs}$ as an integral part of the DHS monitoring and evaluation process. The District B DHO appeared to have a well-structured system of supervision involving assigning specific facilities and geo- graphic areas to individual managers. Participants also reported that they undertook emergency supervisory visits to health centres if the situation on the ground warranted it. There were inconsistencies in the data from District A regarding the frequency of supervision with some respondents indicating that supervision of health centres was done several times in a month while others stated it was done annually. Regardless, respondents from both districts described supervision as being facilitative and program-based; in other words it was used to monitor program implementation and provide technical assistance to those implementing the programs.

No differences were found between the two districts in relation to staff disciplinary matters. In both districts there were formal procedures for managing disciplinary issues, which all respondents reported they followed. Government Regulation No. 53 Year 2010 outlines the course of actions to be taken against civil servants who contravene civil service rules and regulations. Respondents from both districts observed that depending on the nature of violation, disciplinary action could consist of a light, medium or severe reprimand for the staff involved. An absence from work for 16-30 working days without permission, for example, could lead to a delayed salary increase of up to one year, a postponement of promotion for a year, or a demotion to a lower level for a year.

\section{Technical meetings \\ and request for supplies}

Technical meetings were held regularly in both districts according to the DHO level data.
Meetings occurred at least once in a month or more if the situation on the ground required it. These meetings included participants from health centre level, usually the health centre heads. In both districts, specific programs held their own technical meetings to plan or review implementation progress. A record of minutes of larger technical meetings indicating issues discussed and proposed actions to be taken were kept at the DHO and reviewed in following meetings. Respondents from both districts thought technical meetings were effective and useful. Respondents from all the three levels where data were collected indicated that drugs and other essential supplies were requested on time following an established process for requesting materials. The overall availability of drugs in both districts was reported as satisfactory with only occasional shortages especially during disease outbreaks and other emergency situations.

\section{Leadership}

Similar to management practices, there was little difference overall in leadership behaviour between DHO heads, except perhaps in the areas of personal initiative to get things done and fair and consistent dealing with staff disciplinary issues. In these two areas the head of District A DHO scored slightly better than District B (Table 2). Several respondents believed the personal initiative of the District A DHO head had played a role in getting the local government to support district health activities such as the implementation of free medical care for people suffering from dengue and mobiliza-

Table 2. Performance of management and leadership roles by district.

\begin{tabular}{llcc} 
Indicators & $\begin{array}{c}\text { District A } \\
\text { Score }\end{array}$ & $\begin{array}{c}\text { District B } \\
\text { Score }\end{array}$ \\
\cline { 2 - 2 } & 10.0 & 10.0 \\
& Know responsibilities as manager & 9.0 & 5.0 \\
& Have and use procedural manuals & 7.5 & 7.5 \\
Undertake routine staff performance assessment & 7.5 & 7.7 \\
Provide timely feedback on performance & 10.0 & 10.0 \\
Handle staff disciplinary matters effectively & 10.0 & 9.4 \\
Request drugs and supplies on time & 7.0 & 7.5 \\
Undertake regular staff supervision & 10.0 & 10.0 \\
Hold regular technical meetings & 8.0 & 9.1 \\
Use health data for decision making & 8.0 & 6.5 \\
Collaborate with the non-government sectors & 10.0 & 10.0 \\
Leadership & 6.5 & 6.9 \\
& Listen to staff & 5.6 & 6.3 \\
Understand the needs of staff & 8.8 & 8.1 \\
Treat staff as individuals & 9.5 & 7.0 \\
Set good work examples worth emulating & 7.5 & 6.9 \\
Personal initiative to get things done & 8.1 & 7.5 \\
Diligent in handling personnel matters & 10.0 & 7.5 \\
Acknowledge jobs well done & 7.5 & 7.5 \\
Fair and consistent in dealing with staff disciplinary issues & 9.4 & 8.8 \\
Show concern for staff career advancement & &
\end{tabular}


tion of local resources to support high-risk mothers in need of medical care. These initiatives were deemed to have reduced financial and other barriers to accessing health care in the district for these groups.

Overall, both DHO heads appeared to enjoy considerable respect from the health staff in their districts, although there was some reluctance on the part of health centre participants from both districts to say things about the DHO heads that could be perceived as unpleasant. It was also clear that some of the health centre staff had not been in their positions long enough to have a personal view about the head of the DHOs.

\section{Organizational and contextual factors}

There were differences between the two districts in terms of key health system organizational factors including number of health workers, authority over staff, funding adequacy and timely disbursements, and access to transport. However, the differences were not all in favour of District A (the high performing district) as one would expect. Although scores for health workforce numbers and authority over staff were better in District A, timely disbursement of funds from DHO to sub-districts and access to transport favoured District B (Table 3). In both districts respondents generally felt that funding for the DHS was inadequate, and in District A the majority indicated that disbursement was often delayed. Some respondents attributed the problem to a range of issues including unfavorable budget cycle, politics at the regional level, and weakness of the DHO finance office. They all acknowledged, however, that the finance and budget- ing system had improved and that on the whole funding and disbursement processes were getting better.

Workforce numbers were inadequate in both districts but more so in District B than A. Respondents from the two districts indicated that the growing need to provide services previously not provided such as methadone treatment and aged care services, especially in District A, has contributed to the inadequacy. Existing staff had to perform additional roles sometimes in areas they were not trained to cope with the shortage.

There were differences between the two districts in terms of the context in which the health system functioned. District $\mathrm{A}$ is a municipality located just some 25 kilometres away from central Jakarta it is largely one of its suburbs. It also has a smaller population of around 1.5 million that is spread across a 200 square kilometre stretch of land. The proportion of the population living in poverty is relatively low - about 2.4 percent, and the literacy rate is 100 percent. District A also has more private hospitals and limited presence of nongovernment providers. The district's fiscal outlook as illustrated by the Ministry of Finance's fiscal capacity index of 1.2508 (Table 3) is among the best in the West Java province. District $\mathrm{B}$, by contrast, has nearly three times the population of District A (4.3 million) and more than 10 times the landmass. The district's location could not be described as remote since the district capital is only $55 \mathrm{~km}$ away from Jakarta. However, several of the sub-districts are not easily accessed and poverty appears more widespread than in District A. There is also a substantial presence of nonprofit health providers - a further indication of high-unmet health needs.

\section{Discussion}

The similarities in M\&L practices of managers in the two districts raises several issues regarding the contributions of district health managers to the overall performance of DHS and the extent of influence of contextual and other factors. Arguably, because of the common legislative framework (Government Decree No 41/2007) underpinning the appointment and work of heads of local government departments in Indonesia, including DHO heads, there is bound to be some similarities in characteristics of managers and their M\&L practices. The issue of ageing of managers in both districts, for example, may be attributed to the regulations governing the appointment of DHO managers. The district health manager position is a structural position that by law must be occupied by a senior staff member (Echelon II for DHO head and III for unit head). This requirement makes it difficult to appoint a younger person who has not served for many years in the health system irrespective of the district in which they serve. It is therefore not unexpected that most managers were approaching retirement.

The legislation also outlines the functions of DHO heads as local government officials, which include policy development and implementation as well as development of guidelines for implementation..$^{10}$ A review of the written job descriptions of DHO managers from the two districts confirmed that these managers have similar duties and responsibilities. Their main task is to coordinate the implementation of government health policy within the district including coordinate health planning, organise health service delivery, monitor program implementa-

Table 3. Organizational and contextual factors relating to the health systems.

\begin{tabular}{|c|c|c|c|}
\hline & Indicators & District A & District B \\
\hline $\begin{array}{l}\text { Organizational factors } \\
\text { (score) }\end{array}$ & $\begin{array}{l}\text { Adequate and timely disbursement of funds } \\
\text { Adequate number of health workers } \\
\text { Established functional system of procurement and supply } \\
\text { Functional health management information system } \\
\text { Access to transport } \\
\text { Established system of incentives } \\
\text { Authority over staff } \\
\text { Authority over finance }\end{array}$ & $\begin{array}{c}5.0 \\
7.0 \\
10.0 \\
7.0 \\
6.0 \\
7.0 \\
7.0 \\
10.0\end{array}$ & $\begin{array}{c}7.0 \\
5.0 \\
10.0 \\
7.0 \\
7.0 \\
7.0 \\
5.0 \\
10.0\end{array}$ \\
\hline Context & $\begin{array}{l}\text { District population }(\mathrm{N}) \\
\text { Area (land size in } \mathrm{km}^{2} \text { ) } \\
\text { Fiscal capacity of district } \\
\text { Remoteness of district (distance in } \mathrm{km} \text { ) } \\
\text { Proportion of poor population } 2008 \text { (below national poverty line \%) } \\
\text { Education (literacy rate \%) } \\
\text { Size of non-government support for health } \\
\text { Size of private for-profit sector (private hospitals) }\end{array}$ & $\begin{array}{l}1,500,000 \\
200 \\
1.2508 \\
25 \\
2.4 \\
100 \\
\text { Limited } \\
15\end{array}$ & $\begin{array}{c}4,300,000 \\
2371 \\
0.2588 \\
55 \\
13.1 \\
97.6 \\
\text { Substantial } \\
10\end{array}$ \\
\hline
\end{tabular}


tion and assess service performance. Other district health management teams (DHMT) members have similar roles and responsibilities relating specifically to their units or divisions. This may explain why only minor differences exist in the M\&L practices of the managers in the two DHOs.

The law, however, provides for local government heads (bupati) to add to the scope of work of DHO heads based on the needs of the district. Where the needs of individual districts differ, one would expect that the nature and scope of work would also differ to some extent. The lack of any significant differences in M\&L practices in the study districts, despite the differences in health needs, may be interpreted as the district heads (bupati) not exercising their right of adding to the scope of work of DHO heads where necessary.

\section{Effects of context and organizational factors}

The differences in contextual and organizational factors between the two districts provide some explanations for the performance differences. District B (the low-performing district), is relatively disadvantaged in terms of population size, landmass and access to health personnel. With nearly 3 times the population of District A, 10 times the landmass and many rural and remote communities, District B has the more daunting task regarding the delivery of health care. At the very least a significant amount of resources, particularly human resources are required to accomplish efficient and effective health care provision.

Disparities in socio-economic conditions between the two districts also shed light on variations in DHS performance. As a municipality, District A (the high performing district) has a relatively well-developed infrastructure and easy access to health facilities including hospitals in Jakarta. Only $2.4 \%$ of the district population live below the national poverty line (compared to over 13\% in District B) and nearly $87 \%$ of District A households have access to proper sanitation (compared to less that $50 \%$ of households in District B). ${ }^{9}$ The relationship between socio-economic status and health in developing countries has been well-documented. ${ }^{11}$ There is ample evidence that poor people suffer worse health. In Zimbabwe, for example, Woelk and Chikuse ${ }^{12}$ found that stunting, underweight and diarrhoea episodes varied by socioeconomic status with children the lowest socioeconomic group having increased risk of being underweight. Overall, District B's low socioeconomic status may have played a significant role in the relatively low performance of its DHS.

\section{Conclusions}

While no major differences in M\&L practices were found between the two study districts, this should not lead to the conclusion that M\&L practices of district health managers do not affect the overall performance of DHS. It must be emphasized that although the aim of the study was to understand why some DHS perform relatively better than others, it was an exploratory study to test the feasibility of a more comprehensive study, potentially with a nationally representative sample of high- and low-performing districts. To that end, valuable lessons have been learned from the selection of cases and administration of the research instruments. It was clear, however, that context and health system organizational factors crucially influence DHS performance and deserve careful analysis in order to establish the degree of such influence.

\section{References}

1. Segall M. District health systems in a neoliberal world: a review of five key policy areas. Int J Health Plan M 2003;18(S1):S5S26.

2. HISR0. Thailand's universal coverage scheme: achievements and challenges. An independent assessment of the first 10 years (2001-2010). Nonthaburi, Thailand: Health Insurance System Research Office ed.; 2012.

3. Chongsuvivatwong V, Phua KH, Yap MT, et al. Health and health-care systems in southeast Asia: diversity and transitions. Lancet 2011;377:429-37.

4. Heywood P, Choi Y. Health system performance at the district level in Indonesia after decentralization. BMC Int Health Hum Rights 2010;10:3.

5. Day C, Barron P, Massyn N, et al. District health barometer 2010/11. Durban: Health Systems Trust; 2012.

6. MSH. An urgent call to professionalise leadership and management in health care worldwide. Cambridge, MA: Management Sciences for Health; 2006.

7. WHO. Towards better leadership and management in health: report on an international consultation on strengthening leadership and management in low-income countries. Available from: www.who.int/management/ working_paper_10_en_opt.pdf

8. Rokx C, Schieber G, Harimurti P, et al. Health financing in Indonesia: a reform road map. Washington DC: The World Bank; 2009.

9. NIHRD-MoH. Health indicators in Indonesian Jakarta. Jakarta, Indonesia: National Institute of Health Research and Development, Ministry of Health; 2009.

10. Indonesian National Government. Government regulation No. 41/2007 on regional structure of organization. Jakarta, Indonesia: Indonesian National Government; 2007.

11. Gwatkin DR. Health inequalities and the health of the poor: what do we know? What can we do? B World Health Organ 2000;78: 3-18.

12. Woelk G, Chikuse P. Using demographic and health surveys (DHS) data to describe intra country inequalities in health status: Zimbabwe. Mid-Rand, South Africa: EQUINET; 2000. Available from: http://www. equinetafrica.org/bibl/docs/P0L09equity.pdf 